\title{
A AGRICULTURA FAMILIAR E O TRIPÉ MULTIFUNCIONAL-PLURIATIVA-SUSTENTÁVEL: ATIVIDADES NÃO AGRÍCOLAS TRANSFORMANDO O ESPAÇO AGRÍCOLA
}

\author{
Family farming and the multifunctional tripod - pluriative - sustainable: non-agricultural \\ activities transforming agricultural space
}

\author{
Elba Medeiros Punski dos Santos* \\ Ana Maria Marques Camargo Marangoni** \\ *Doutoranda do PPG em Geografia, USP - empsantos@uneb.br \\ **Docente do PPG em Geografia, USP - ana.marangoni@terra.com.br
}

\author{
Recebido em 10/04/2019. Aceito para publicação em 20/04/2019. \\ Versão online publicada em 26/04/2019 (http://seer.ufrgs.br/paraonde)
}

\begin{abstract}
Resumo:
Aliando a preocupação mundial com a sustentabilidade e a alimentação saudável aos resultados iniciais insatisfatórios do Programa Nacional de Fortalecimento da Agricultura Familiar (Pronaf), instituições brasileiras planejaram transformações, tanto no processo produtivo quanto na forma de geração de renda, abrangendo, com o crédito do programa, a multifuncionalidade e a pluriatividade sob o contexto da sustentabilidade territorial. Este artigo objetiva discutir essas questões e seu impacto na dinâmica espacial e nas atividades não agrícolas, e a forma com que esses fenômenos são contemplados nas políticas para o setor.
\end{abstract}

Palavras-chave: Agricultura Familiar, Sustentabilidade, Multifuncionalidade Rural.

\begin{abstract}
:
Combining the international concern with sustainability and healthy food to poor initial results of the National Programme for the Strengthening of Family Agriculture (Pronaf), brazilian institutions planned transformations, both in the production process and in the form of income generation, covering, with the program's credit, the multifunctionality and the multiple activities under the context of territorial sustainability. This article aims to discuss these issues and your impact on the space and dynamics in nonagricultural activities, and how these phenomena are covered in the policies for the sector.
\end{abstract}

Key-words: Family Agriculture, Sustainability, Rural Multifunctionality.

\section{Introdução}

A agricultura familiar no Brasil ocupa um elevado contingente de pessoas e possui grande potencial de produção de alimentos e geração de renda. É um segmento heterogêneo que possui numerosos tipos diferentes de agricultores e complexidades próprias, e essa diversidade se reflete não só em escala regional, mas também territorial e local.

O Ministério do Desenvolvimento Social (MDS) define a agricultura familiar como uma forma de produção, na qual os agricultores familiares dirigem o processo produtivo, destacando a diversificação e utilizando o trabalho dos membros da família, usualmente complementado pelo trabalho assalariado. 
Inúmeros estudos têm apontado para as disparidades existentes entre agricultores familiares e não familiares (patronais), em diversos aspectos, desde a área do estabelecimento até a integração aos mercados e acesso ao crédito. Em função dessas diferenças, que se reproduzem nos desiguais resultados produtivos e de geração de renda, o governo brasileiro decidiu diferenciar as condições do crédito rural de acordo com o perfil socioeconômico do produtor. A partir daí, foi criado o Programa Nacional de Fortalecimento da Agricultura Familiar (Pronaf), primeira política pública destinada exclusivamente aos agricultores familiares.

Simultaneamente, movimentos e manifestações mundiais atingiram a agricultura, iniciando uma transformação que se direcionou, de forma mais acentuada, para o setor dos pequenos e médios produtores. Duas dessas manifestações foram decisivas para essas transformações. A primeira foi o Ciclo Uruguai de negociações internacionais, no qual surgiram as primeiras referências aos aspectos não comerciais da agricultura, que originou um acordo incluindo dois desses aspectos: a segurança alimentar e a proteção do meio ambiente (AIRES FILHO, 2004). A segunda foi a Conferência Rio-92, na qual se debateu as consequências econômicas, sociais e ambientais do processo de modernização da agricultura, consideradas como destruidoras do meio ambiente, contrárias à alimentação saudável e socialmente excludente. Essas discussões respaldaram o propósito do desenvolvimento rural sustentável.

A noção de multifuncionalidade da agricultura surgiu associada a ações de apoio ao pequeno agricultor em sua dependência do mercado, interagindo algumas funções, como por exemplo, a manutenção de um modo característico de viver e de produzir e a preservação ambiental e do patrimônio cultural. Dessa forma, a atividade agrícola não se limita à produção agropecuária, mas se estende também à oferta de serviços e bens (materiais e imateriais) à sociedade (CARNEIRO; MALUF, 2005 p. 43).

Em relação à pluriatividade, Schneider (2005 p. 26) a considera como "um fenômeno que pressupõe a combinação de duas ou mais atividades, sendo uma delas a agricultura". Essa interação entre atividades agrícolas e não agrícolas se intensificam quanto "mais complexas e diversificadas forem as relações entre os agricultores e o ambiente social e econômico em que estiverem situadas, tornando a pluriatividade um fenômeno heterogêneo e diversificado".

Por sua vez, resumidamente, a sustentabilidade está relacionada ao desenvolvimento econômico e material sem agressão ao meio ambiente, usando os recursos naturais de forma que se mantenham no futuro. Em outras palavras, a sustentabilidade é uma alternativa para garantir a sobrevivência dos recursos naturais do planeta, ao mesmo tempo permitindo às sociedades soluções ecológicas de desenvolvimento.

Moreira (1996) considera que as questões atuais sobre ecologia e meio ambiente, direcionam a processos de revalorização da natureza e das propriedades a elas associadas. Acredita-se, portanto, que o fato de se compreender a agricultura familiar como o setor mais ajustado ao desenvolvimento sustentável, amplia a complexidade socioeconômica que envolve o setor.

Aliando esses novos conceitos aos resultados iniciais insatisfatórios do Pronaf, instituições brasileiras planejaram transformações, tanto no processo produtivo quanto na forma de geração de renda, abrangendo, com o crédito do programa, a multifuncionalidade e a pluriatividade sob o contexto da sustentabilidade territorial.

Quantidade significativa de agricultores familiares brasileiros vai além da produção agropecuária, em razão da insuficiência da renda agrícola para o sustento da família. É preciso questionar de que forma as características, julgadas como propícias para o enquadramento do setor no tripé multifuncionalidade, pluriatividade, desenvolvimento territorial sustentável, estão sendo consideradas pelas políticas públicas. É necessário ir mais além, é preciso saber se realmente o setor possui essas características, se tem potencial e condições de desenvolvê-las e em que escala geográfica.

Este artigo objetiva discutir essas questões e seu impacto na dinâmica espacial e nas atividades

ParaOnde!?, Porto Alegre, v.11, n.1, p.83-89, 2019. http://seer.ufrgs.br/paraonde

Edição Especial: “Geografia e transformações socioespaciais: dinâmicas agrárias e políticas do desenvolvimento regional” 
não agrícolas, e a forma com que esses fenômenos são contemplados nas políticas para o setor, apontando alguns resultados parciais obtidos na pesquisa em desenvolvimento sobre Políticas Agrícolas e Agricultura Familiar, no curso de doutorado em Geografia na Faculdade de Filosofia, Letras e Ciências Humanas da Universidade de São Paulo.

Está dividido em três partes, além desta Introdução. No segundo tópico discute-se a multifuncionalidade, a pluriatividade e a sustentabilidade territorial, de forma sucinta, conceituandoas e situando suas funções e desempenhos no âmbito da agricultura familiar. A terceira parte contém a conceituação do desenvolvimento sustentável, suas contradições no contexto das políticas de desenvolvimento rural e sua aplicação no desenvolvimento sustentável territorial. Por fim, nas considerações finais, questiona-se a ênfase dada aos agricultores familiares como agentes dessas políticas e seus novos ingredientes, apontando as fragilidades do setor e os equívocos institucionais na sua implementação.

\section{Multifuncionalidade, pluriatividade e Sustentabilidade Territorial}

Cazella et all (2009) comenta que a noção de multifuncionalidade considera outras funções desempenhadas pela agricultura, que vão além da produção de alimentos e da conservação dos recursos naturais. 0 conceito considera também a coesão sociocultural nos territórios e a "construção-manutenção" da paisagem rural, valorizando e promovendo as funções socioambientais desempenhadas pela agricultura familiar. De acordo com o autor, destacam-se três aspectos relevantes desse conceito: a segurança alimentar, a proteção ao meio ambiente e a função social da agricultura. Esses são aspectos impactantes no setor agrícola alimentar em escala mundial e no Brasil.

O conceito de segurança alimentar, definido pela FAO, é a condição para todos os seres humanos terem, a qualquer momento, acesso físico e econômico à alimentação suficiente, saudável e nutritiva, que satisfaça suas necessidades básicas para uma vida saudável e ativa. Como cabe ao Estado garantir à sua população o acesso à alimentação, a segurança alimentar é considerada um bem público.

A necessidade da proteção do meio ambiente é uma noção consensual, reconhecida pela grande maioria dos países, em razão dos efeitos negativos da utilização intensiva de produtos químicos, que distanciaram os produtos agrícolas dos padrões de alimentação saudável. A resistência ao consumo desse tipo de produto estimula a incorporação da função ambiental na agricultura e justifica a prática de proteção ao meio ambiente, integrado à produção agrícola.

A outra característica relevante da multifuncionalidade, a função social da agricultura considerada a que apresenta maiores dificuldades - é observada na criação de empregos e geração de renda, contribuindo para a diminuição da migração do campo para a cidade. Considerado como ator potencial para encarregar-se da segurança alimentar, a permanência do agricultor familiar no campo torna-se vital. Consequentemente, é essencial que esses empregos estejam coligados às atividades agrícolas, como uma forma de estimular o exercício dessas atividades e evitar a evasão, principalmente dos jovens. Essa evasão já se aponta de forma preocupante, criando estudos e pesquisas sobre o processo sucessório no campo.

A multifuncionalidade depende das características de cada região. Na Europa, as políticas multifuncionais objetivam a manutenção da paisagem, a proteção do meio ambiente e a qualidade dos alimentos. Nos EUA, ela é relacionada à paisagem rural, estilo de vida do campo e preservação do meio ambiente. No Brasil, também se percebe influências regionais. Próximo às grandes cidades distingue-se chácaras e sítios com função de lazer e moradia, onde as atividades agrícolas se caracterizam como uma atividade secundária. 0 turismo rural é outra forma de remuneração das atividades de lazer proporcionadas pela agricultura. Na região da serra gaúcha brasileira, por exemplo, o turismo relacionado à produção de vinhos tem se revelado como atividade 
complementar significativa à agricultura (SANTOS et all, 2012).

Nas áreas mais distantes dos grandes centros, em especial nas regiões Norte e Nordeste do Brasil, as atividades multifuncionais são mais relacionadas com as funções de segurança alimentar e geração de emprego e renda, como complementação das atividades agrícolas.

Em relação à pluriatividade, Schneider a define como:

um fenômeno através do qual membros das famílias que habitam no meio rural optam pelo exercício de diferentes atividades, ou, mais rigorosamente, pelo exercício de atividades não-agrícolas, mantendo a moradia no campo e uma ligação, inclusive produtiva, com a agricultura e a vida no espaço rural. Nesse sentido, ainda que se possa afirmar que a pluriatividade seja decorrente de fatores que lhe são exógenos, como o mercado de trabalho não agrícola, ela pode ser definida como uma prática que depende de decisões individuais ou familiares (SCHNEIDER, 2003 p. 112).

Mattei (1999) afirma que essas outras atividades desenvolvidas no setor agrícola romperam com a hegemonia da agricultura no mundo rural. Dois fatos, citados pelo autor, contribuíram para o surgimento das famílias pluriativas. 0 primeiro foi consequência da modernização e da integração produtiva, que elevaram a produtividade do trabalhador e liberou mão de obra nas famílias. 0 segundo, o aumento do número de agricultores e familiares ocupados em atividades não diretamente relacionadas à agricultura e a consequente combinação das atividades agrícolas com atividades não agrícolas, tanto interna quanto externamente às propriedades familiares.

Essas transformações no mundo rural passaram a ser consideradas na elaboração das políticas para o desenvolvimento rural, incluindo os agricultores familiares como atores potenciais para esse desenvolvimento, cujo planejamento acontece na escala territorial e conta com recursos do Pronaf.

Sobre a sustentabilidade territorial, Magnaghi (2003) destaca que ela é mais complexa que a sustentabilidade ambiental, pois um sistema territorial é considerado sustentável quando não interfere no funcionamento de outro sistema. Portanto, a sustentabilidade territorial deve ser avaliada considerando, principalmente, o grau de autonomia e poder de inclusão dos atores.

O conceito de sustentabilidade é composto pelas esferas social, econômica e ambiental, e "não deve ser vista apenas na esfera ambiental" e sua delimitação "em outras esferas isoladas" devem ser visualizadas de forma integrada, principalmente quando se trata de sustentabilidade territorial. Dessa forma, questiona-se se a literatura (e as políticas) não está segmentando "um conceito que deveria ser tratado de maneira uniforme" (FLORES E MEDEIROS, 2009 p.4-5, parênteses nosso). De acordo com as autoras, a segmentação pode ser usada "até mesmo para dar a devida dimensão ao termo", mas o que não se deve "é considerar que ao trabalhar algumas sustentabilidades, estaremos trabalhando a sustentabilidade territorial como um todo".

\section{As políticas e o desenvolvimento rural sustentável}

Desde a década de 1980, a sustentabilidade tem sido contemplada nos processos de desenvolvimento pelos programas e ações públicas, principalmente porque - conforme visto anteriormente - o meio ambiente tornou-se preocupação mundial.

De acordo com Bonnal e Maluf (2009), os programas públicos atribuem diversos e contrastantes significados ao desenvolvimento sustentável, que se refletem na elaboração e implementação dos programas de desenvolvimento territorial. Apesar da relevância e obrigatoriedade do tema, ainda não se conseguiu "a plena incorporação do componente ambiental em todas as dimensões requeridas para se chegar a uma concepção de desenvolvimento territorial sustentável [...]". O enfoque do desenvolvimento sustentável nas estratégias do Ministério do Desenvolvimento Agrário (MDA) exigiu uma visão mais integrada de território, desnecessária num enfoque de proteção ambiental.

ParaOnde!?, Porto Alegre, v.11, n.1, p.83-89, 2019. http://seer.ufrgs.br/paraonde

Edição Especial: “Geografia e transformações socioespaciais: dinâmicas agrárias e políticas do desenvolvimento regional” 
(op. cit. p. 214).

Ainda de acordo com os autores, o enfoque territorial na formulação e implementação dos programas rurais foi acompanhado pela noção de multifuncionalidade, conforme o plano de reforma agrária e Programa de Desenvolvimento Socioambiental da Produção Familiar Rural (Proambiente), vinculado ao Ministério do Meio Ambiente.

Porém, os elevados índices de pobreza rural, as restrições no acesso à terra, a ampliação das exportações agropecuárias, o avanço do reflorestamento e a produção de agrocombustíveis, "são fatores que restringem a incorporação do enfoque da multifuncionalidade" (BONNAL E MALUF, 2009 p. 229), além de restringirem questões relacionadas à sustentabilidade ambiental.

As pequenas propriedades têm função importante em várias escalas da sustentabilidade ligadas ao desenvolvimento social e econômico do território. De acordo com Flores e Medeiros, os programas do governo destacam ações de desenvolvimento e inclusão como, por exemplo, a agroindústria familiar, por intermédio do PRONAF, "que não necessariamente atendem às demandas de sustentabilidade ecológica/ambiental" (ibid. 2009 p. 7).

Muitos problemas referentes às questões ambientais, relacionados com o espaço rural e com a agricultura familiar, constituem obstáculos para as práticas produtivas sustentáveis no setor. Nas pequenas unidades produtivas a questão ambiental pode gerar conflitos como, por exemplo, manter áreas de preservação em tamanho reduzido dessas propriedades.

O Mapa da Injustiça Ambiental e Saúde no Brasil, desenvolvido em conjunto pela Fundação Oswaldo Cruz (Fiocruz) e Federação de Órgãos para Assistência Social e Educacional (Fase), com o apoio do Ministério da Saúde, revela que no Brasil há maior ocorrência de conflitos socioambientais em áreas rurais do que em áreas urbanas, basicamente em razão de atividades do agronegócio, da mineração e das obras de infraestrutura, como hidrelétricas e rodovias. Esses conflitos atingem, principalmente, as populações dos campos, das regiões florestais ou costeiras, tais como agricultores familiares, indígenas, quilombolas, pescadores artesanais e ribeirinhos (RAMMÉ, 2012). Os recentes desastres ambientais ocorridos em Mina Gerais oriundos das barragens de mineração da Cia. Vale do Rio Doce confirmam os argumentos do autor.

Nesses casos, percebe-se que as políticas públicas dão maior enfoque e importância ao crescimento econômico, mais do que ao desenvolvimento, sustentável ou não.

\section{Considerações Finais}

A importância do setor agropecuário familiar é reconhecida não só pela produção dos alimentos, mas também pela geração de emprego. Porém, talvez em consequência da menor escala produtiva e da pouca inovação tecnológica, as discussões sobre o setor são direcionadas para o social, fortalecendo as opiniões de que os programas a eles destinados deveriam ter a função política de inclusão social.

De forma generalizada, inclusão social é considerada como um conjunto de ações que garante a participação igualitária de todos na sociedade, em todos os setores, tais como saúde, educação, justiça, segurança, entre outros. Porém, nenhum desses elementos se consegue através de política de créditos. Portanto, concorda-se com os autores que argumentam que o crédito não é instrumento de superação da pobreza e que os recursos do Pronaf, por exemplo, deveriam ser destinados àqueles que demandam crédito, ou seja, que tenham produção estruturada e interação comercial. 0 crédito tem a função da inclusão no mercado que, por sua vez, pode alavancar a inclusão social, aí sim, se houver aquele conjunto de ações governamentais para esse fim.

Na prática, os programas governamentais buscam a inclusão econômica, principalmente quando direcionam seus objetivos para o desenvolvimento, em qualquer escala. Não é diferente com os

ParaOnde!?, Porto Alegre, v.11, n.1, p.83-89, 2019. http://seer.ufrgs.br/paraonde

Edição Especial: “Geografia e transformações socioespaciais: dinâmicas agrárias e políticas do desenvolvimento regional” 
agricultores familiares. Dufumier $(2010$ p. 10) argumenta que a população participa verdadeiramente dos programas quando seus interesses são atendidos, sendo que "a falta de incentivos materiais reais é a principal causa da passividade e do imobilismo de muitos produtores". Aliando esse argumento do autor às pesquisas empíricas, realmente se constata que o interesse primordial dos agricultores familiares é sua inclusão econômica, como forma de conseguir todos os outros ingredientes que lhe permitirão obter o modo de vida sonhado e a que têm direito.

A possibilidade de encaixe da agricultura familiar na multifuncionalidade e no desenvolvimento territorial sustentável se deu porque, com menor escala produtiva e pouca inovação tecnológica, esses agricultores são considerados "pequenos" e, consequentemente, mais próximos e "harmonizados" com o meio ambiente, portanto mais suscetíveis a transformações e a investidas políticas de interesse.

Dessa forma, novos papéis foram atribuídos ao setor, mas questiona-se se os agricultores familiares têm condições e potencial para executar os programas. A multifuncionalidade e a produção orgânica, por exemplo, que poderiam apoiar a sustentabilidade da produção agrícola familiar, nem sempre tem aceitação entre os produtores, mesmo com recursos do Pronaf, pouco contribuindo com o processo de desenvolvimento territorial ou nas questões ambientais. 0 número significativo de produtores e municípios excluídos dessas dinâmicas evidencia a limitação desse modo de produção, talvez pela pressão das entidades envolvidas para a produção orgânica nos territórios que, por sua vez, revela a falta de participação dos agricultores nas decisões (BONNAL E MALUF, 2009).

Em vista do exposto e com base em experiências vividas e resultados de pesquisas publicadas sobre o tema, coloca-se em questão o parecer do governo, que o território seria a melhor unidade para impulsionar diversos atores a tomar as iniciativas orientadas para o desenvolvimento, implementando múltiplas transformações. É questionável essa afirmativa, principalmente em função das divergências e desconfianças, que culmina na inexpressiva participação desses atores, na maioria dos territórios, nos programas de desenvolvimento. A pluriatividade, segundo dados estatísticos do Instituto Brasileiro de Geografia e Estatística (IBGE, 2006) tem maior expressividade nos meio da agricultura familiar, chegando mesmo a contribuir, de forma quase total, na geração de renda dessas famílias, através do trabalho assalariado fora da unidade familiar.

O foco espacial, em qualquer escala, na atividade multifuncional ou na forma de produção, deve se juntar ao cuidado com a qualidade de vida dos agricultores familiares, geralmente analisada sob as condições e escolhas dos indivíduos. É necessário abranger os aspectos político e de poder a essas dimensões, reconhecendo suas diferenças espaciais. Isso pode ser contemplado por esses programas, que também devem enfatizar o apoio governamental e valorizar a assistência técnica de qualidade e o estudo do solo e do seu potencial produtivo.

Mais do que tudo, é preciso que os tomadores de decisão reconheçam a capacidade que esses agricultores familiares têm de enfrentar - e vencer - os desafios para melhorar suas condições de trabalho e vida. Para isso é preciso conhecê-los e conhecer a vocação do lugar a que pertencem.

\section{Referências}

AIRES FILHO, Benaias. Multifuncionalidade da agricultura: um conceito em construção ou um pretexto protecionista? 42을 Congresso da Sociedade Brasileira de Economia, Administração e Sociologia Rural (Sober), 2004. http://www.sober.org.br/palestra/12/100449.pdf. Acesso em agosto de 2016.

BONNAL, Philippe e MALUF, Renato S. Políticas de desenvolvimento territorial e multifuncionalidade da agricultura familiar no Brasil. Política \& Sociedade n. 14 Dossiê. Santa Catarina: UFSC, 2009.

Para0nde!?, Porto Alegre, v.11, n.1, p.83-89, 2019. http://seer.ufrgs.br/paraonde

Edição Especial: "Geografia e transformações socioespaciais: dinâmicas agrárias e políticas do desenvolvimento regional" 
CARNEIRO, Maria José e MALUF, Renato S. Multifuncionalidade da agricultura familiar. Em BOTELHO FILHO, Flávio Borges (org.). Agricultura Familiar e Desenvolvimento Territorial: Contribuições ao Debate. v. 5. n. 17. Núcleo de Estudos Avançados. Brasília: UnB, 2005.

CAZELLA, Ademir A., BONNAL, Philippe e MALUF, Renato S. (orgs.). Agricultura familiar: multifuncionalidade e desenvolvimento territorial no Brasil. Rio de Janeiro: Mauad X, 2009.

DUFUMIER, Marc. Projetos de Desenvolvimento Agrícola. Salvador: EDUFBA, 2010.

FLORES, Shana S. e MEDEIROS, Rosa M. V. Desenvolvimento territorial sustentável: uma abordagem sobre sustentabilidade na agricultura. Em V Encontro de Grupos de Pesquisa Agricultura, desenvolvimento regional e transformações sócioespaciais. Santa Maria, RS: UFSM, 2009.IBGE - Instituto Brasileiro de Geografia e Estatística. Censo Agropecuário, 2006.

MAGNAGHI, Alberto. Le projet local. Pierre Mardaga: Sprimont, 2003.

MATTEI, Lauro F. Pluriatividade e desenvolvimento rural no Estado de Santa Catarina. Tese de Doutorado em Economia. Campinas: Unicamp, 1999.

MDS - Ministério do Desenvolvimento Social. Agricultura familiar. Acesso à informação. www.mds.gov.br (consultado em janeiro de 2017).

MOREIRA, Roberto J. Agricultura familiar e sustentabilidade: valorização e desvalorização econômica e cultural das técnicas. Campina Grande: 18º Encontro da Apipsa, 1996.

RAMMÉ, Rogério S. Da justiça ambiental aos direitos e deveres ecológicos. Caxias do Sul, RS: Educs, 2012. www.ucs.br/site/midia/arquivos/justica_ambiental_educs_ebook.pdf. Acesso em julho de 2016.

SANTOS, Eric Gumes L., COUTO, Vitor de Athayde, ROCHA, Alynson S. A multifuncionalidade e a questão agrária no Brasil: uma análise da agricultura familiar como geradora das novas funções da agricultura. www.sober.org.br/palestra/2/1031.pdf acessado em outubro/2014.

SCHNEIDER, Sérgio. Teoria Social, Agricultura Familiar e Pluriatividade. São Paulo: Revista Brasileira de Ciências Sociais, vol. 18 no 51, fev/2003.

A pluriatividade e o desenvolvimento rural brasileiro. Em BOTELHO FILHO, Flávio B. (org.). Agricultura Familiar e Desenvolvimento Territorial: contribuições ao debate, v.5 n.17. Brasília: UnB, 2005. 